\title{
The prospective effects of workplace violence on physicians' job satisfaction and turnover intentions: the buffering effect of job control
}

\author{
Tarja Heponiemi ${ }^{1 *}$, Anne Kouvonen ${ }^{2,3}$, Marianna Virtanen $^{4}$, Jukka Vänskä ${ }^{5}$ and Marko Elovainio ${ }^{1}$
}

\begin{abstract}
Background: Health care professionals, including physicians, are at high risk of encountering workplace violence. At the same time physician turnover is an increasing problem that threatens the functioning of the health care sector worldwide. The present study examined the prospective associations of work-related physical violence and bullying with physicians' turnover intentions and job satisfaction. In addition, we tested whether job control would modify these associations.

Methods: The present study was a 4-year longitudinal survey study, with data gathered in 2006 and 2010.The present sample included 1515 (61\% women) Finnish physicians aged 25-63 years at baseline. Analyses of covariance (ANCOVA) were conducted while adjusting for gender, age, baseline levels, specialisation status, and employment sector.

Results: The results of covariance analyses showed that physical violence led to increased physician turnover intentions and that both bullying and physical violence led to reduced physician job satisfaction even after adjustments. We also found that opportunities for job control were able to alleviate the increase in turnover intentions resulting from bullying.

Conclusions: Our results suggest that workplace violence is an extensive problem in the health care sector and may lead to increased turnover and job dissatisfaction. Thus, health care organisations should approach this problem through different means, for example, by giving health care employees more opportunities to control their own work.
\end{abstract}

Keywords: Job control, Work-related violence, Psychosocial resources, Intentions to quit, Physicians

\section{Background}

Health care professionals, including physicians, are at high risk of encountering workplace violence. For example, 59 per cent of Australian general practitioners reported that they had experienced work-related violence during the previous 12 months [1]. In US emergency departments, 75 per cent of physicians had encountered verbal violence and 28 per cent indicated that they had been victims of physical assault in the previous 12 months [2]. In another study, 96 per cent of physician respondents in US emergency departments reported experiencing verbal violence and 78 per cent a verbal threat during the previous 6 months [3]. In a study conducted among hospital and community physicians in Israel, 56 per cent reported verbal violence and 9 per cent physical assault during the

\footnotetext{
* Correspondence: Tarja.heponiemi@thl.fi

'National Institute for Health and Welfare, P.O. Box 30, Helsinki 00271, Finland Full list of author information is available at the end of the article
}

previous year [4]. In Finland, every fifth physician reported having encountered physical violence or the threat of it in the previous year [5].

Workplace violence may have many negative ramifications for health care employees. Workplace violence has been associated with lower job satisfaction and higher levels of turnover intentions in nurses and home healthcare assistants [6,7]. Moreover, workplace violence has been found to affect negatively hospital personnel's health [8] and increase sickness absences [9]. In physicians, workrelated violence has been shown to lead to reduced job satisfaction and a decline in job performance [10]. In addition, among healthcare professionals, workplace violence may lead to difficulties in listening to patients, rumination, poor concentration, and intrusive thoughts [11], as well as impact negatively on family life and quality of life [4].

From the health care sector's point of view, tackling workplace violence encountered by physicians is important 
given that it can lead to lower job satisfaction and increased turnover. Physician turnover is an increasing problem that threatens the functioning of the health care sector worldwide. Physician turnover may lead to decreased productivity, decreased quality of care and to an increased need to recruit and train new physicians. This is costly and may affect health outcomes $[12,13]$. In the US it has been estimated that the minimum cost of turnover may represent a loss of over 5 per cent of the total annual operating budget, due to hiring and training costs and productivity loss [14].

Job control refers to job and organisational characteristics, such as the employee's decision-making authority, opportunities to participate, and opportunities to use skills and knowledge. Job control may have direct effects on job attitudes, health and wellbeing. In a study among Finnish anaesthesiologists, job control appeared as one of the most important work-related factors in relation to physicians' work-related wellbeing [15]. Previous studies have repeatedly demonstrated the importance of job control for employees' health. For example, low job control has been associated with increased myocardial infarction risk [16], increased heart disease risk [17], higher blood pressure [18], and to greater fibrinogen responses to stress [19]. Moreover, low job control has been associated with an increased number of sick-leave spells [20] and with poorer self-rated health eight years later [21]. In a study among emergency physicians, psychological health was not affected by the number and nature of hours worked but by the ability to control working hours and the perceived flexibility of the workplace [22].

High job control at work may protect employees from developing job dissatisfaction and psychiatric distress [23]. High job control may additionally increase organisational commitment [24] and decrease work-related anger [25]. A positive change in job control over a 4-year period was associated with higher levels of physical activity and selfrated health and lower levels of distress [26]. Job control has also been associated with job performance and ability to learn [27]. In addition, previous studies have shown that low control opportunities may affect employees' attitudes to staying in or leaving a job, given that low job control has been associated with increased levels of retirement intentions $[28,29]$. In addition, job control has been found to mitigate retirement intentions associated with poor health and low work ability among physicians [30].

High job control may be viewed as a potential coping factor that helps distressed employees cope with demanding situations and, thus, lessen their job dissatisfaction and intentions to quit. According to Spector [31], job control can affect a person's choice of coping strategy in a way that perceived high control is likely to lead to constructive coping, whereas lack of control is more likely to lead to destructive coping. Previous studies have indeed associated job control with successful coping [32,33] and successful coping, in turn, has been associated with fewer turnover intentions in demanding and stressful situations, such as with organisational change [34,35].

Job control may provide flexibility to avoid certain tasks that have a high risk of violence and to take breaks from work, which helps employees to regulate emotional responses and reappraise work challenges more positively [36]. Frese [37] has suggested that control enables a person to perform the most stressful tasks when that person feels particularly able to do them; that is, people can adjust the situation according to their needs, and can, therefore, be more relaxed in their work. Control may also act as a safety signal, given that a person with a high degree of control knows that he or she is able to change the situation if it becomes too difficult, thus knowing that the conditions may never be worse than he or she is willing to withstand [38]. Thus, many opportunities to control one's job may act as a buffer against the negative effects of stressful working conditions like as work-related violence.

The aim of the present study was to examine the associations of work-related violence (physical violence and bullying) with turnover intentions and job satisfaction in a four-year follow-up among Finnish physicians. Specifically, we were interested to see whether job control would modify these associations. We hypothesised that both physical violence and bullying would be associated with increased levels of turnover intentions and decreased job satisfaction. We additionally hypothesised that job control would act as a buffer for these negative effects of workrelated violence.

\section{Methods}

The present study is part of the Finnish Health Care Professionals Study, in which we drew a random sample of 5000 physicians in Finland (30\% of the whole physician population) from the 2006 database of physicians maintained by the Finnish Medical Association. The register covers all licensed physicians in Finland. Phase 1 data were gathered with postal questionnaires in 2006 (Figure 1). Non-respondents were twice sent a reminder and copy of the questionnaire. Responses were received from 2841 physicians (response rate 57\%). The sample is representative of the eligible population in terms of age, gender, and employment sector [39].

Phase 2 took place four years later in 2010, with data gathered using either a web-based or a traditional postal survey. At phase 1 the respondents were asked their permission to participate in follow-up surveys and 2206 agreed. Those who had died or had incorrect address information were excluded $(\mathrm{N}=37)$, thus, at phase 2 the survey was sent to 2169 physicians. First, an e-mail invitation to participate in the web-based survey was sent, followed by two reminders. For those who did not respond to these a postal questionnaire was then sent once. E-mail and 


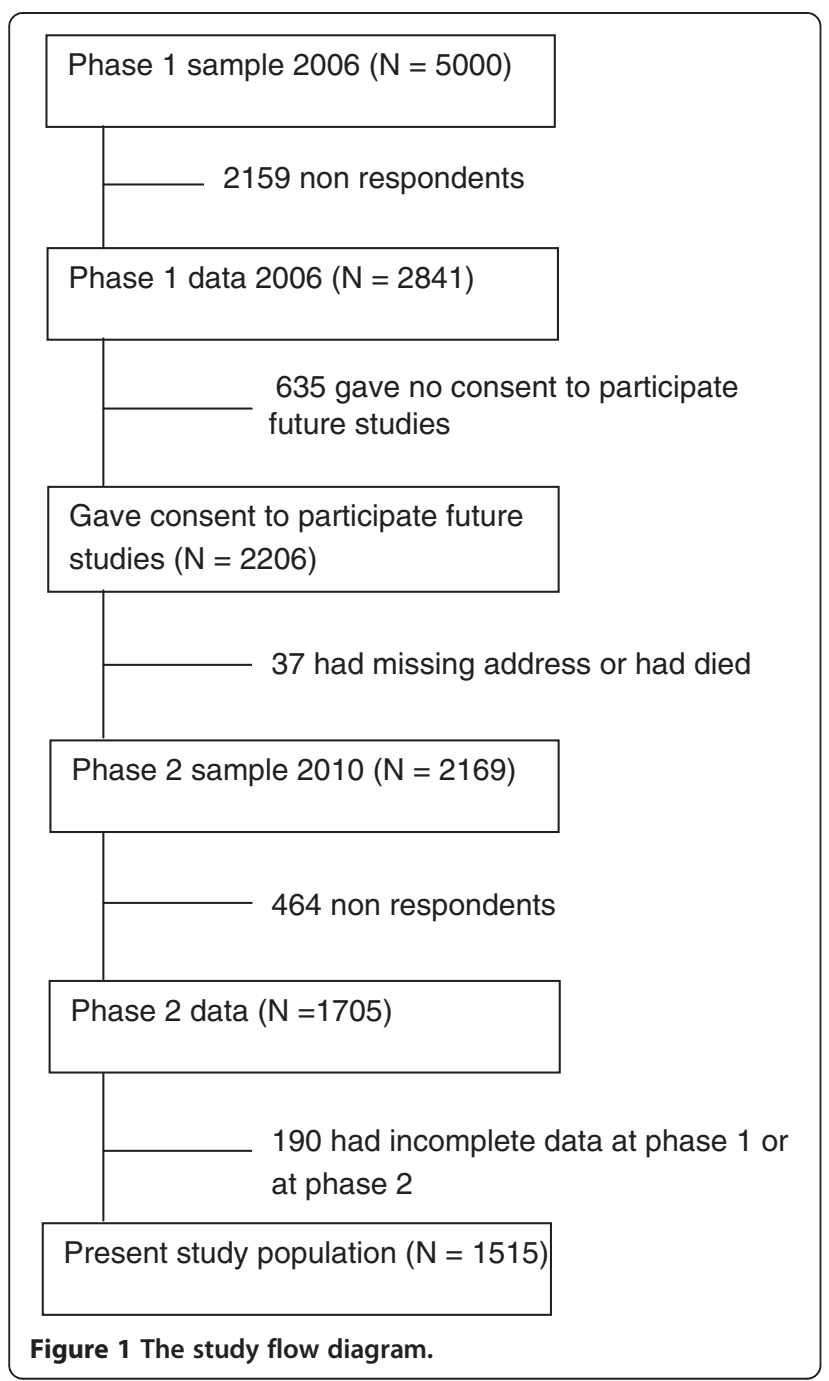

postal addresses were obtained from the Finnish Medical Association. The total number of respondents was 1705 (response rate 79\%), of which 1018 (60\%) answered the web-based and 687 (40\%) the postal questionnaire (the response format is adjusted for in the analyses). Of these, 190 had incomplete data and were excluded; the final study sample therefore includes 1515 physicians (61\% women) aged $25-63$ years (mean $=45.7$ years) $(2006)$. Ethical approval for this study was obtained from the Ethical Review Board of the National Institute for Health and Welfare.

\section{Measures}

The present study used violence variables, job control, baseline turnover intentions, baseline job satisfaction, and covariates from phase 1 . The outcome (turnover intentions and job satisfaction) variables were taken from phase 2 .

Job satisfaction was assessed with the mean of 3 items derived from Hackman and Oldham's [40] Job Diagnostic Survey on a 5-point scale, ranging from 1 (totally disagree) to 5 (totally agree). Cronbach's alpha coefficient for this study was 0.66 at phase 1 and 0.88 at phase 2 (an example of the items: "I am generally satisfied with my work.")

Turnover intentions were measured with the mean of three questions concerning willingness to (a) change to other physician work, (b) to another profession, and (c) to quit $(\alpha=0.61$ at phase 1 and 0.66 at phase 2$)$. The response alternatives were " $1=$ no, $2=$ perhaps, and $3=$ yes".

Physical violence was measured with a question asking whether the respondent had experienced work-related violence (such as kicking and hitting) or had been threatened with it and how often. Responses were coded as: $0=$ never, $1=$ less than once a year, $2=$ once a year or more often. Bullying was asked with the following question: "Psychological violence means continuous repetitive bullying, victimising or offending treatment. Are you now or have you previously been a target of this kind of psychological violence and bullying in your own work?" The answer options were $0=$ no and $1=$ yes.

Job control was measured by combining the skill discretion (6 items) and decision authority (3 items) scales derived from Karasek's Job Content Questionnaire JCQ [41]. Skill discretion measures how much the job requires skill, creativity, task variety, and learning of new skills (e.g., "My job requires that I learn new things"). Decision authority measures the freedom to make independent decisions and possibilities to choose how to perform work (e.g., "I have a lot of say about what happens in my job"). The items were rated on a 5-point Likert-scale, ranging from 1 (totally disagree) to 5 (totally agree) $(\alpha=$ 0.76 at phase 1$)$.

Covariates included gender, age, specialisation status (specialist, specialisation on-going, and not specialised), and employment sector (hospital, primary care, and other).

\section{Statistical analyses}

Analyses of covariance (ANCOVA) were conducted, with turnover intentions at phase 2 as the dependent variable, and physical violence, bullying, job control, gender, age, baseline turnover intentions, response format, specialisation status, and employment sector from phase 1 were included as independent variables. The analyses were conducted in four steps. In the first step, the univariate effects of physical violence, bullying, and job control for turnover intentions were examined in separate analyses (Model A). A second step included all the above-mentioned variables and gender, age, baseline turnover intentions, and response format (Model B). In the third step, specialisation status and employment sector were additionally added to the former model (Model C). Finally, the interactions of job control with physical violence and bullying were added (Model D). A similar series of ANCOVAs were generated with job satisfaction at phase 2 as for the dependent variable. 


\section{Results}

Table 1 shows the characteristics of the study sample. Sixty-one per cent had encountered physical violence in their career and 19 per cent had encountered bullying. The majority of the participants (77\%) were specialised physicians and 46 per cent worked in hospitals, 22 per cent in primary care, and 32 per cent in other healthcare settings. The within-subjects differences in turnover intention and job satisfaction levels between phase 1 and phase 2 were examined with GLM repeated measures analyses. Analyses showed that job satisfaction levels had increased $(\mathrm{F}=35.2, \mathrm{p}<0.001)$ and turnover intentions had decreased $(\mathrm{F}=23.2, \mathrm{p}<0.001)$ during the study period.

Table 2 shows the results from the ANCOVA models for turnover intentions. Physical violence and bullying were associated with more turnover intentions, and job control was associated with less turnover intentions. However, only

\section{Table 1 Characteristics of the study sample}

\begin{tabular}{|c|c|}
\hline & n (\%) \\
\hline \multicolumn{2}{|l|}{ Physical violence at phase 1} \\
\hline No & $596(39)$ \\
\hline Less than once a year & $731(48)$ \\
\hline Once a year or more often & $188(13)$ \\
\hline \multicolumn{2}{|l|}{ Bullying at phase 1} \\
\hline No & $1233(81)$ \\
\hline Yes & $282(19)$ \\
\hline \multicolumn{2}{|l|}{ Gender } \\
\hline Women & $918(61)$ \\
\hline Men & $597(39)$ \\
\hline \multicolumn{2}{|l|}{ Response format at phase 2} \\
\hline Internet & $922(61)$ \\
\hline Post & $593(39)$ \\
\hline \multicolumn{2}{|l|}{ Specialisation status at phase 1} \\
\hline Not specialised & $166(11)$ \\
\hline Specialisation on-going & $176(12)$ \\
\hline Specialised & $1170(77)$ \\
\hline \multicolumn{2}{|l|}{ Employment sector at phase 1} \\
\hline Hospital & $694(46)$ \\
\hline Primary care & $328(22)$ \\
\hline \multirow[t]{2}{*}{ Other } & $493(32)$ \\
\hline & Mean (SD) \\
\hline Age at phase 1 & $45.7(9.5)$ \\
\hline Turnover intentions at phase 1 (1-3) & $1.54(0.56)$ \\
\hline Turnover intentions at phase $2(1-3)$ & $1.46(0.52)$ \\
\hline Job satisfaction at phase $1(1-5)$ & $3.96(0.71)$ \\
\hline Job satisfaction at phase $2(1-5)$ & $4.03(0.83)$ \\
\hline Job control at phase 1 (1-5) & $3.95(0.51)$ \\
\hline
\end{tabular}

the association between physical violence and turnover intentions persisted after adjusting for baseline level, response format, demographics and work-related variables. Older respondents were less likely to have turnover intentions than their younger counterparts.

The interaction between bullying and job control was significant for turnover intentions. As Figure 2 shows, job control was not related to increased turnover intentions among those who had not encountered bullying, whereas among those who had encountered bullying, job control was associated with turnover intention levels. That is, the highest levels of turnover intentions were among those who had low job control opportunities and had encountered bullying.

Table 3 shows the results from the ANCOVA models for job satisfaction. Physical violence and bullying were associated with lower levels of job satisfaction, and job control was associated with higher levels of job satisfaction. These associations persisted even after adjusting for baseline level, response format, demographics and workrelated variables. Older respondents, those who answered by post, and those who worked in an employment sector other than hospitals or primary care were more likely to be satisfied with their jobs than their counterparts. The interactions with job control were not significant for job satisfaction.

\section{Discussion}

The present four-year longitudinal study showed that workplace physical violence and bullying were associated with decreased job satisfaction and increased turnover intentions among Finnish physicians. In addition, we found that opportunities to control one's job were able to alleviate the increase in turnover intentions resulting from bullying.

Our results highlight the importance of job control as a buffer of negative psychosocial working environments. In addition, we found that job control was directly related to higher job satisfaction but the association between job control and turnover intentions did not remain significant after adjusting for baseline turnover intentions and demographics. Also previous studies have reported that job control is an important buffer. For example, high job control has been found to mitigate retirement intentions resulting from poor health and low work ability among Finnish physicians [30]. Furthermore, in a previous study high job control has been found to alleviate intentions to change profession that were associated with distress and sleeping problems [42]. Potential mechanisms behind this effect of job control could, for example, be that job control affects coping strategies, gives flexibility to avoid certain tasks and to take breaks to regulate emotional responses, gives possibilities to choose when to perform stressful tasks, and gives the assurance that a stressful situation can be changed if it gets intolerable [31,36-38]. 
Table 2 The results of the analyses of covariance for turnover intentions

\begin{tabular}{|c|c|c|c|c|c|c|c|c|}
\hline & \multicolumn{2}{|c|}{ Model $A^{a}$} & \multicolumn{2}{|c|}{ Model B ${ }^{b}$} & \multicolumn{2}{|c|}{ Model C $C^{c}$} & \multicolumn{2}{|c|}{ Model $D^{d}$} \\
\hline & $F$ & $p$ & $F$ & $p$ & $F$ & $p$ & $F$ & $p$ \\
\hline Physical violence & 19.8 & $<0.001$ & 6.8 & 0.001 & 7.1 & 0.001 & 1.5 & 0.232 \\
\hline Bullying & 11.9 & $<0.001$ & 3.5 & 0.062 & 3.0 & 0.083 & 6.8 & 0.009 \\
\hline Job control & 31.2 & $<0.001$ & 0.3 & 0.584 & 0.1 & 0.735 & 1.9 & 0.166 \\
\hline Gender & & & 0.2 & 0.682 & 0.2 & 0.608 & 0.5 & 0.498 \\
\hline Age & & & 29.6 & $<0.001$ & 33.1 & $<0.001$ & 34.2 & $<0.001$ \\
\hline Baseline turnover intentions & & & 279.0 & $<0.001$ & 278.4 & $<0.001$ & 274.1 & $<0.001$ \\
\hline Response format & & & 3.5 & 0.063 & 3.7 & 0.056 & 3.3 & 0.069 \\
\hline Specialisation status & & & & & 2.8 & 0.064 & 2.9 & 0.055 \\
\hline Employment sector & & & & & 1.0 & 0.380 & 0.8 & 0.468 \\
\hline Physical violence* Job control & & & & & & & 0.8 & 0.453 \\
\hline Bullying*Job control & & & & & & & 5.7 & 0.017 \\
\hline$R^{2}$ & & & & 0.23 & & 0.23 & & 0.23 \\
\hline
\end{tabular}

${ }^{a}$ Model $A$ included univariate effects.

${ }^{\mathrm{b}}$ Model B included physical violence, bullying, job control, gender, age, baseline turnover intentions, and response format.

${ }^{c}$ Model $C$ included variables from model $A$ and specialisation status and employment sector.

${ }^{\mathrm{d}}$ Model $\mathrm{D}$ included in addition to Model C also interactions physical violence*job control and bullying*job control.

Job control could be improved by giving employees a greater variety of tasks, opportunities to fully use and develop their skills, and a stronger voice in decisions. For example, participative decision-making has been introduced as a method to increase job control [43] along with greater freedom over start and finish times, more discretion over how tasks are performed, and autonomous or self-regulated work teams [44]. Young and Leese [45] have proposed greater flexibility as a potential solution for the problems in retention and recruitment of general practitioners. They suggested that flexibility could be improved by a) varying the time commitment across the working day and week (part-time, job-share, temporary, and shortterm), b) offering wider choice of long-term career paths, c) offering more education and training, and d) widening

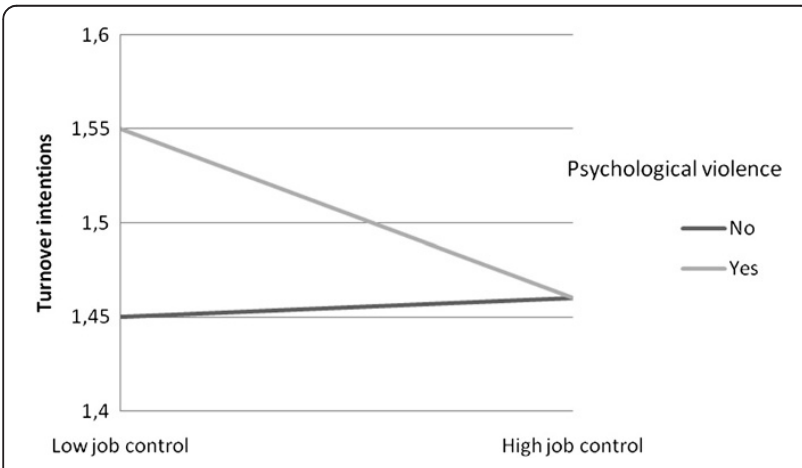

Figure $\mathbf{2}$ The interaction between bullying and job control for turnover intentions. Estimated marginal means among those scoring low (below median) and high (above median) in job control adjusted for baseline level, response format, demographics, and work-related variables. the scope of remuneration and contract conditions. In a similar way, Shanafelt et al. [46] highlighted the importance of job autonomy as the central organisational characteristic that promotes well-being in physicians; they suggest that physicians should be provided with increased opportunity to influence their work environment, to participate in decisions, and to have more control over schedules.

Workplace violence is a big problem in health care and organisations should pay more attention to these issues. For example, in our study over sixty per cent of physicians had encountered physical violence in their career and approximately one in five had encountered bullying in the previous year. Targeting efforts at increasing control opportunities could alleviate the negative effects of workplace violence. Nevertheless, direct actions are also needed to actually decrease violence in workplaces. For example, metal detectors, security dog teams, cameras, and security personnel have been suggested to improve health care personnel's security [47]. Hoag-Apel [48] suggested appointing a risk assessment team and staff training on, for example, body language, being alert to the tone of voice, and not taking anger personally. It has also been shown that reducing staff stress by improving staff's cognitive efficiency and emotional control can lead to reduced violence [49].

In the present study, we found that physical violence led to increased turnover intentions and both bullying and physical violence led to reduced job satisfaction even after adjustments. Previous findings have associated physical violence, bullying, and verbal violence with both lower levels of job satisfaction and higher turnover intentions $[6,7,10,50]$. However, the previous findings were from cross-sectional studies, while our results here confirm that work-related violence also has longitudinal effects. 
Table 3 The results of the analyses of covariance for job satisfaction

\begin{tabular}{|c|c|c|c|c|c|c|c|c|}
\hline & \multicolumn{2}{|c|}{ Model $A^{a}$} & \multicolumn{2}{|c|}{ Model $B^{b}$} & \multicolumn{2}{|c|}{ Model C ${ }^{c}$} & \multicolumn{2}{|c|}{ Model $D^{d}$} \\
\hline & $\mathrm{F}$ & $p$ & $\mathrm{~F}$ & $p$ & $F$ & $p$ & $\mathrm{~F}$ & $p$ \\
\hline Physical violence & 14.4 & $<0.001$ & 5.6 & 0.004 & 4.8 & 0.009 & 0.2 & 0.799 \\
\hline Bullying & 24.7 & $<0.001$ & 10.2 & 0.001 & 9.9 & 0.002 & 2.4 & 0.123 \\
\hline Job control & 81.2 & $<0.001$ & 6.4 & 0.011 & 6.0 & 0.015 & 5.8 & 0.016 \\
\hline Gender & & & 0.2 & 0.648 & 0.1 & 0.716 & 0.2 & 0.664 \\
\hline Age & & & 6.5 & 0.011 & 9.6 & 0.002 & 9.8 & 0.002 \\
\hline Baseline job satisfaction & & & 142.0 & $<0.001$ & 136.0 & $<0.001$ & 134.4 & $<0.001$ \\
\hline Response format & & & 5.4 & 0.020 & 5.3 & 0.022 & 5.1 & 0.024 \\
\hline Specialisation status & & & & & 2.5 & 0.079 & 2.6 & 0.074 \\
\hline Employment sector & & & & & 3.2 & 0.039 & 3.3 & 0.038 \\
\hline Physical violence* Job control & & & & & & & 0.1 & 0.950 \\
\hline Bullying* Job control & & & & & & & 1.2 & 0.265 \\
\hline$R^{2}$ & & & & 0.16 & & 0.16 & & 0.16 \\
\hline
\end{tabular}

${ }^{a}$ Model $A$ included univariate effects.

${ }^{\mathrm{b}}$ Model B included physical violence, bullying, job control, gender, age, baseline job satisfaction, and response format.

${ }^{c}$ Model $C$ included variables from model $A$ and specialisation status and employment sector.

${ }^{\mathrm{d}}$ Model $\mathrm{D}$ included in addition to Model $\mathrm{C}$ also interactions physical violence*job control and bullying*job control.

We found that older respondents were more satisfied with their jobs and were less likely to have turnover intentions than younger respondents. This corresponds well with previous findings among physicians [51-54]. In our study gender was unrelated to both job satisfaction and turnover intentions. Previous studies have found mixed results: Among German and Norwegian hospital physicians, gender was unrelated to job satisfaction [52], whereas among German general practitioners women had higher levels of job satisfaction than men [54]. In Chinese physicians, men had a higher likelihood of turnover intentions compared to women [53]. Moreover, we found that physicians working in hospitals and primary care were less satisfied than physicians from other sectors. This is congruent with a previous study showing that private sector physicians had higher levels of job satisfaction and organisational commitment and lower levels of psychological distress and sleeping problems compared to physicians working in the public sector [51].

The present study relied on self-reported measures, which may lead to problems associated with an inflation of the strengths of relationships and with the common method variance. In our study we were not able to differentiate between violence from patients or customers and violence from co-workers. Regarding workplace bullying the source is more likely to be co-workers than with physical violence. The effects of violence may vary depending on the source of violence, especially regarding bullying; that is, the effects of bullying might be different when caused by patients than when caused by co-workers. This issue should be investigated in future studies. Moreover, violence measures were collected 4 year prior to turnover intentions and we did not discriminate within the study population as to whether there were changes in violence experience over the course of the study frame. Therefore, it is possible that this may have caused a misclassification bias in our results. However, it is likely that this bias might simply weaken the associations found.

Moreover, although we controlled for age, gender, response format, specialisation status, and employment sector we cannot rule out the possibility of residual confounding. The present study used both a web-based and a more traditional postal survey to gather follow-up data. This is a limitation of the study. However, we controlled for this response format in the analyses. The use of webbased surveys is increasing, but they often result in low response rates, thus combining them with postal questionnaires might help to elevate response rates. There may be differences in response styles between the response formats and therefore it would be important to adjust for response format in analyses. Future studies about the subject are needed.

\section{Conclusions}

Our results suggest that promoting employees' control opportunities in health care organisations might help to provide a buffer against the negative effects of workplace violence on turnover intentions in physicians. In addition, we showed that physical violence and bullying has longitudinal effects on job satisfaction and turnover intentions. Workplace violence is an extensive problem especially in the health care sector and organisations should approach this problem through multiple means, such as, by giving health care employees more opportunities to control their own work, in addition to direct measures. 


\section{Competing interests}

All authors declare that they have no competing interest.

\section{Authors' contributions}

$\mathrm{TH}$ designed the study, directed its implementation, performed analyses and led all aspects of the work, including data analysis and writing. AK and ME contributed to planning the data analyses. AK, JV, MV and ME helped to conceptualise the ideas, interpret findings, and write and critically review drafts of the article. All authors read and approved the final manuscript.

\section{Acknowledgements}

This study was supported by the Finnish Work Environment Fund and the Academy of Finland (project 128002).

\section{Author details}

${ }^{1}$ National Institute for Health and Welfare, P.O. Box 30, Helsinki 00271, Finland. ${ }^{2}$ School of Sociology, Social Policy and Social Work, Queen's University Belfast, Northern Ireland, UK. ${ }^{3}$ UKCRC Centre of Excellence for Public Health (NI), Queen's University Belfast, Belfast, UK. ${ }^{4}$ Finnish Institute of Occupational Health, Helsinki, Finland. ${ }^{5}$ Finnish Medical Association, Helsinki, Finland.

Received: 20 November 2012 Accepted: 14 January 2014

Published: 17 January 2014

\section{References}

1. Magin PJ, May J, McElduff P, Goode SM, Adams J, Cotter GL: Occupational violence in general practice: a whole-of-practice problem. Results of a cross-sectional study. Aust Health Rev 2011, 35(1):75-80.

2. Kowalenko T, Walters BL, Khare RK, Compton S: Workplace violence: a survey of emergency physicians in the state of Michigan. Ann Emerg Med 2005, 46:142-147.

3. Gates DM, Ross CS, McQueen L: Violence against emergency department workers. J Emerg Med 2006, 31(3):331-337.

4. Carmi-lluz T, Peleg R, Freud T, Shvartzman P: Verbal and physical violence towards hospital- and community-based physicians in the Negev: an observational study. BMC Health Serv Res 2005, 5:54.

5. Kajantie M, Vänskä J: Työpaikkaväkivalta kohdistuu nuoriin lääkäreihin [Workplace violence focuses on young doctors]. Finnish Medical Journal 2006, 10:1121-1125

6. Quine L: Workplace bullying in nurses. J Health Psychol 2001, 6:73-84

7. Sherman MF, Gershon RR, Samar SM, Pearson JM, Canton AN, Damsky MR: Safety factors predictive of job satisfaction and job retention among home healthcare aides. J Occup Environ Med 2008, 50(12):1430-1441.

8. Kivimäki M, Virtanen M, Vartia M, Elovainio M, Vahtera J, Keltikangas-Jarvinen L: Workplace bullying and the risk of cardiovascular disease and depression. Occup Environ Med 2003, 60(10):779-783.

9. Kivimäki M, Elovainio $M$, Vahtera J: Workplace bullying and sickness absence in hospital staff. Occupational Environmental Medicine 2000, 57(10):656-660.

10. Mirza NM, Amjad Al, Bhatti AB, Mirza FT, Shaikh KS, Kiani J, Yusuf MM, Khan MU, Nazir ME, Assad Q, et al: Violence and abuse faced by junior physicians in the emergency department from patients and their caretakers: a nationwide study from Pakistan. J Emerg Med. In press.

11. Coles J, Koritsas S, Boyle M, Stanley J: GPs, violence and work performance - 'just part of the job?'. Aust Fam Physician 2007, 36(3):189-191.

12. Misra-Hebert AD, Kay R, Stoller JK: A review of physician turnover: rates, causes, and consequences. Am J Med Qual 2004, 19(2):56-66.

13. Temkin-Greener $\mathrm{H}$, Winchell M: Medicaid beneficiaries under managed care: provider choice and satisfaction. Health Serv Res 1991, 26:509-529.

14. Waldman JD, Kelly F, Arora S, Smith HL: The shocking cost of turnover in health care. Health Care Manage Rev 2004, 29(1):2-7.

15. Lindfors PM, Meretoja OA, Töyry SM, Luukkonen RA, Elovainio MJ, Leino TJ: Job satisfaction, work ability and life satisfaction among Finnish anaesthesiologists. Acta Anaesthica Scandinavica 2007, 51(7):815-822.

16. Malinauskiene V, Theorell T, Grazuleviciene R, Malinauskas R, Azaraviciene A: Low job control and myocardial infarction risk in the occupational categories of Kaunas men, Lithuania. J Epidemiol Community Health 2004 58(2):131-135

17. Bosma H, Stansfeld SA, Marmot MG: Job control, personal characteristics, and heart disease. J Occup Health Psychol 1998, 3(4):402-409.
18. Steptoe A, Willemsen G: The influence of low job control on ambulatory blood pressure and perceived stress over the working day in men and women from the Whitehall II cohort. J Hypertens 2004, 22(5):915-920.

19. Steptoe A, Kunz-Ebrecht S, Owen N, Feldman PJ, Willemsen G, Kirschbaum C, Marmot M: Socioeconomic status and stress-related biological responses over the working day. Psychosom Med 2003, 65(3):461-470.

20. Arola H, Pitkänen M, Nygård $\mathrm{CH}$, Huhtala $\mathrm{H}$, Manka ML: The connection between age, job control and sickness absences among Finnish food workers. Occup Med 2003, 53(3):229-230.

21. Smith PM, Frank JW, Mustard CA, Bondy SJ: Examining the relationships between job control and health status: a path analysis approach. J Epidemiol Community Health 2008, 62(1):54-61.

22. Taylor DM, Pallant JF, Crook HD, Cameron PA: The psychological health of emergency physicians in Australasia. Emergency Medicine Australasiansis 2004, 16(1):21-27.

23. Johnson JV, Hall EM, Ford DE, Mead LA, Levine DM, Wang NY, Klag MJ: The psychosocial work environment of physicians. The impact of demands and resources on job dissatisfaction and psychiatric distress in a longitudinal study of Johns Hopkins Medical School graduates. J Occup Environ Med 1995, 37(9):1151-1159.

24. Jalonen P, Virtanen M, Vahtera J, Elovainio M, Kivimaki M: Predictors of sustained organisational commitment among nurses with temporary job contracts. J Nurs Adm 2006, 36(5):268-276.

25. Fitzgerald ST, Haythornthwaite JA, Suchday S, Ewart CK: Anger in young black and white workers: effects of job control, dissatisfaction, and support. J Behav Med 2003, 26(4):283-296.

26. Smith P, Frank J, Bondy S, Mustard C: Do changes in job control predict differences in health status? Results from a longitudinal national survey of Canadians. Psychosom Med 2008, 70(1):85-91.

27. Bond FW, Flaxman PE: The ability of psychological flexibility and job control to predict learning, job performance, and mental health. J Organisational Behav Manage 2006, 26:113-130.

28. Elovainio M, Forma P, Kivimäki M, Sinervo T, Sutinen R, Laine M: Job demands and job control as correlates of early retirement thoughts in Finnish social and health care employees. Work Stress 2005, 19:84-92.

29. Sutinen R, Kivimäki M, Elovainio M, Forma P: Associations between stress at work and attitudes towards retirement in hospital physicians. Work \& Stress 2005, 19:177-185.

30. Heponiemi T, Kouvonen A, Vänskä J, Halila H, Sinervo T, Kivimäki M, Elovainio M: Health, psychosocial factors and retirement intentions among Finnish physicians. Occup Med 2008, 58:406-412.

31. Spector PE: Employee control and occupational stress. Curr Dir Psycholog Science 2002, 11:133-136.

32. Daniels C, Huang GD, Feuerstein M, Lopez M: Self-report measure of low back-related biomechanical exposures: clinical validation. J Occup Rehabil 2005, 15(2):113-128.

33. Theorell T, Westerlund $H$, Alfredsson L, Oxenstierna G: Coping with critical life events and lack of control-the exertion of control. Psychoneuroendocrinology 2005, 30(10):1027-1032.

34. Cunningham GB: The relationships among commitment to change, coping with change, and turnover intentions. Eur J Work and Organisational Psychology 2006, 15:29-45.

35. Fugate M, Kinicki AJ, Prussia GE: Employee coping with organisational change: an examination of alternative theoretical perspectives and models. Pers Psychol 2008, 61:1-36.

36. Daniels K: Coping and the job-demands-control-support model: an exploratory study. Int J Stress Manag 1999, 6:125-144.

37. Frese M: Theoretical models of control and health. In Job control and worker health. Edited by Sauter SL, Hurrel JJ Jr, Cooper CL. New York: Wiley; 1989.

38. Miller SM: Controllability and human stress: method, evidence and theory. Behav Res Ther 1979, 17:287-304.

39. Elovainio M, Heponiemi T, Vänskä J, Sinervo T, Kujala S, Laakso E, Jalonen P, Hakanen J, Husman K, Töyry S, et al: [How well are Finnish physicians in the 21st century?] Kuinka suomalainen lääkäri voi 2000-luvulla? Suom Laakaril 2007, 20-21:2071-2076.

40. Hackman JR, Oldham GR: Development of the Job diagnostic survey. J Appl Psychol 1975, 60(2):159-170.

41. Karasek R: Job Content Questionnaire and user's quide. Lowell, MA: University of Massachusetts, Department of Work Environment Massachusetts; 1985.

42. Heponiemi T, Kouvonen A, Vänskä J, Halila H, Sinervo T, Kivimäki M, Elovainio M: The association of distress and sleeping problems with 
physicians' intentions to change profession: the moderating effect of job control. J Occup Health Psychol 2009, 14:365-373.

43. Lowin A: Participative decision making: a model, literature critique, and prescriptions for research. Organ Behav Hum Perform 1968, 3:68-106.

44. Sparks K, Faragher B, Cooper CL: Well-being and occupational health in the 21st century workplace. J Occup Organisational Psychology 2001, 74:489-509.

45. Young $R$, Leese $B$ : Recruitment and retention of general practitioners in the UK: what are the problems and solutions? Br J Gen Pract 1999, 49(447):829-833.

46. Shanafelt TD, Sloan JA, Habermann TM: The well-being of physicians. Am J Med 2003, 114(6):513-519.

47. Stirling G, Higgins JE, Cooke MW: Violence in A\&E departments: a systematic review of the literature. Accid Emerg Nurs 2001, 9(2):77-85.

48. Hoag-Apel CM: Violence in the emergency department. Nurs Manage 1998, 29(7):60-63.

49. Paterson B, Turnbull J, Aitken I: An evaluation of a training course in the short-term management of violence. Nurse Educ Today 1992, 12(5):368-375.

50. Driscoll RJ, Worthington KA, Hurrell JJ: Workplace assault: an emerging job stressor. Consulting Psychology J: Pract Res 1995, 47:205-212.

51. Heponiemi T, Kuusio H, Sinervo T, Elovainio M: Job attitudes and well-being among public vs. private physicians: organisational justice and job control as mediators. Eur J Public Health, 21(4):520-525.

52. Rosta J, Nylenna M, Aasland OG: Job satisfaction among hospital doctors in Norway and Germany. A comparative study on national samples. Scand J Public Health 2009, 37(5):503-508.

53. Zhang $Y$, Feng $X$ : The relationship between job satisfaction, burnout, and turnover intention among physicians from urban state-owned medical institutions in Hubei, China: a cross-sectional study. BMC Health Serv Res 2011, 11:235.

54. Goetz K, Musselmann B, Szecsenyi J, Joos S: The influence of workload and health behavior on job satisfaction of general practitioners. Fam Med 2013, 45(2):95-101

\section{doi:10.1186/1472-6963-14-19}

Cite this article as: Heponiemi et al:: The prospective effects of workplace violence on physicians' job satisfaction and turnover intentions: the buffering effect of job control. BMC Health Services Research 2014 14:19.

\section{Submit your next manuscript to BioMed Central and take full advantage of:}

- Convenient online submission

- Thorough peer review

- No space constraints or color figure charges

- Immediate publication on acceptance

- Inclusion in PubMed, CAS, Scopus and Google Scholar

- Research which is freely available for redistribution 